\title{
La boîte d'herboriste
}

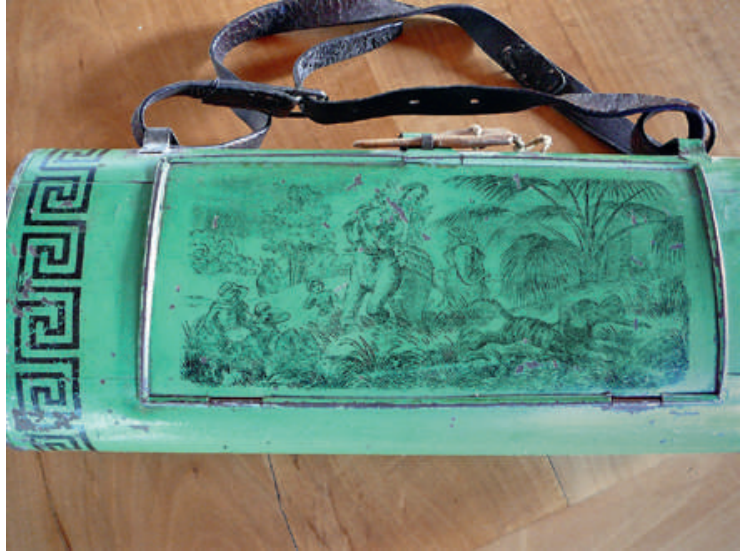

Imaginez une boîte d'herboriste cylindrique, peinte en vert, équipée de lanières en cuir, avec un couvercle rabattu orné d'une peinture de chasse au tigre et une pièce de bois pour fermer: elle pourrait être portée par un de nos ancêtres, muni d'un bâton et disciple de Linné. C'est en effet avec ce type de boîte que le grand botaniste a complété sa connaissance des plantes médicinales, exploré la flore et la faune, étoffé généreusement son herbier et enfermé nombre d'insectes. Cet objet trône désormais, inutile, sur une étagère, aussi poussiéreux que les livres qui feront bientôt figure d'antiquités face aux e-books.

Linné a écrit un guide, «Philosophia botanica», sur la libre collecte des plantes, un petit manuel que Goethe prenait lui aussi comme vade-mecum. Il contient des conseils pratiques sur les vêtements et les outils, une mise en garde contre les heures chaudes et recommande de manger vers deux heures puis de se reposer jusqu'à quatre heures. Ces différentes instructions ignorent les lois sur les brevets, et «tout ce qui rampe et vole» n'est pas revendiqué comme étant la propriété du chercheur.

C'est en 1873 seulement qu'est délivré pour la première fois un brevet sur un organisme vivant, à savoir la levure isolée de Louis Pasteur. Les anciens botanistes se seraient sans doute ralliés à la coalition «Pas de brevet sur les semences», qui a transmis plus de 70000 signatures au président du Parlement européen en septembre 2012. Les prochains mois, le parlement délibérera sur un brevet unitaire. Cette coalition, comptant plus de deux cents organisations, dont beaucoup d'origine suisse, souhaite améliorer la défense des horticulteurs, des agriculteurs et des consommateurs. Elle demande, dans sa pétition, que l'accès au matériel destiné à l'élevage et à la culture et la vente de semences et d'animaux de rente ne puissent être gênés par les brevets.

Depuis 1989, l'Office européen des brevets (OEB) accorde des brevets sur des plantes et des animaux. Les directives de 1998 stipulent que l'invention doit avoir une orientation nouvelle, être commercialement utilisable et constituer une étape innovante. Sont exclues les variétés végétales, races animales et inventions agissant sur la ligne germinale de l'être humain, les méthodes de traitement opérationnelles et thérapeutiques et la modification de l'identité génétique animale sans intérêt fondamental. Beaucoup de processus et de critères ne sont pas clairement définis, pour la plus grande joie des juristes et des lobbyistes de toutes sortes qui s'engouffrent dans la faille. L'OEB a déjà accordé plusieurs centaines de brevets sur des animaux et des plantes génétiquement modifiés, et a même commencé à en délivrer pour des plantes ordinaires sans modification génétique. D'un côté, les brevets doivent protéger les droits de propriété intellectuelle, donc stimuler l'industrie biotechnologique. De l'autre, le droit des brevets freine la concurrence et favorise les monopoles d'entreprises comme Monsanto, Syngenta ou Bayer BioScience, ou de ministères de l'agriculture de certains pays. Des précédents sur des procédures controversées touchent actuellement les brocolis, les tomates, les porcs, les vaches, les tournesols, les melons et autres plantes utiles. Les brevets devraient au moins être évités sur les cultures et élevages conventionnels. Mais les brevets biotechnologiques ne se limitent pas à l'agriculture. La souris oncogène fut le premier animal transgénique, avec un oncogène dans son génome. Elle a tout d'abord été brevetée aux USA, puis en Europe en 2004, en arguant du fait que le bénéfice pour l'être humain était beaucoup plus important que les scrupules moraux sur la souffrance de l'animal. Distribués avec trop de prodigalité, les brevets finissent par aller à l'encontre de l'intention initiale de protection. L'augmentation du nombre de brevets dans le domaine des Life Sciences influence la sélection des thèmes de recherche, dans la mesure où ces derniers ont tendance à être orientés vers des objectifs susceptibles d'être brevetés, donc rentables. Et le libre échange d'informations et de matériel de base est de plus en plus entravé, à cause des demandes d'indemnisation.

Les conséquences sur la politique de l'évolution et la société sont également discutables. Les botanistes et herboristes du passé sont aujourd'hui comparables à des peuples indigènes, dont l'environnement et les connaissances traditionnelles sont exploités comme base pour de nouvelles inventions. La biodiversité ellemême est en jeu quand la monopolisation et l'industrialisation monoculturelle de l'élevage d'animaux et de la culture de plantes supplantent les variétés locales adaptées. Les joies de la découverte ont rapidement diminué. Linné a recommandé aux cueilleurs de plantes et aux ramasseurs d'insectes une boîte fermant bien, avec une large ouverture pour la main. Le cadenas n'était pas prévu. Il ne connaissait pas encore l'usage que comptaient faire les biopirates de ces boîtes d'herboristes, dans un avenir lointain.

Erhard Taverna 